\title{
ÓLEO DE SOJA E ÓLEO DE SOJA RESIDUAL EM DIETAS PARA OVINOS CONFINADOS: PARÂMETROSSANGUÍNEOS
}

\author{
SOYBEAN OIL AND RESIDUAL SOYBEAN OIL IN DIETS FOR FEEDLOT SHEEP: \\ BLOODPARAMETERS
}

\author{
Scarpino, F.B.O. ${ }^{1 *}$; Ezequiel, J.M.B. ${ }^{1}$; Silva, D.A.V. ${ }^{1}$ e van Cleef, E.H.C.B. ${ }^{2}$ \\ 'Universidade Estadual Paulista Júlio de Mesquita Filho. Câmpus Jaboticabal. São Paulo. Brasil. \\ *flascarpino@hotmail.com \\ ${ }^{2}$ Kansas State University. Manhattan, Kansas. USA.
}

Palavras chave adicionais

Alimentos alternativos. Cordeiros. Sangue.

\section{RESUMO}

Objetivou-se neste trabalho avaliar o efeito da inclusão de 2 fontes lipídicas (óleo de soja e óleo de soja residual) na dieta de ovinos confinados sobre os parâmetros sanguíneos. Foram utilizados 24 borregos Santa Inês × Dorper, machos, não castrados, distribuídos em delineamento em blocos casualizados e submetidos a três dietas experimentais: $\mathrm{C}=$ dieta controle, volumoso:concentrado na proporção de $40: 60 ; S=C$ com inclusão de $6 \%$ de óleo de soja; e R= C com inclusão de 6 $\%$ de óleo de soja residual de fritura. Silagem de milho foi utilizada como volumoso e o concentrado era composto por milho grão inteiro, casca de soja, farelo de girassol, ureia, sal mineral, calcário e antioxidante. Os animais foram confinados por 105 dias, sendo que no dia 59 foram realizadas colheitas de sangue através de punção da veia jugular para quantificação de glicose, triglicérides, colesterol e proteínas totais, além das enzimas hepáticas aspartato aminotransferase (AST), gama glutamiltransferase (GGT) e fosfatase alcalina (FAL). A inclusão de $6 \%$ de óleo de soja ou de óleo residual na dieta aumentou as concentrações sanguíneas de colesterol e da AST $(p<0,01)$, e a FAL tendeu a aumentar $(p=0,06)$ quando óleo residual foi utilizado. Porém, tais alterações não foram suficientes para causarem prejuízos na saúde animal.

\section{SUMMARY}

The objective of this study was to evaluate the effects of 2 dietary lipid sources (soybean oil and

\section{AdDitional KEYWORDS}

Alternative feed. Blood. Lambs.

residual soybean oil) on blood parameters of feedlot sheep. It were used 24 male lambs Santa Inês $\times$ Dorper, uncastrated, distributed in a randomized block design and assigned to three experimental diets: $\mathrm{C}=$ control diet, composed by forage concentrate ratio of $40: 60, S=C$ with $6 \%$ of soybean oil, and $\mathrm{R}=\mathrm{C}$ with $6 \%$ of frying oil. Corn silage was the roughage and concentrate was composed by whole corn grain, soybean hulls, sunflower meal, urea, mineral salt, limestone, and antioxidant. The animals were kept in individual pen for 105 days, and at day 59 blood samples were collected by jugular vein puncture for quantification of glucose, triglycerides, cholesterol, total protein, and liver enzymes AST (aspartate aminotransferase), GGT (gamma glutamyl transferase) and FAL (alkaline phosphatase). Inclusion of $6 \%$ of soybean oil or frying oil in diet increased the concentration of cholesterol and AST $(p<0.01)$; FAL tended $(p=0.06)$ to increase when residual oil was used. However, such changes are not sufficient to cause damage to animal health.

\section{INTRODUÇÃO}

A intensificação dos sistemas de produção de carne ovina acarreta consequências positivas como redução na idade de abate, carne de melhor qualidade, aumento no giro de capital, além do aproveitamento de adubo orgânico. Porém, no 


\section{SCARPINO, EZEQUIEL, SILVA E VAN CLEEF}

sistema de confinamento torna-se necessária a utilização em maior proporção de alimentos concentrados, o que consequentemente aumenta os custos da produção.

Para que ocorra a redução destes custos, é comum o uso de ingredientes alternativos na alimentação dos animais. O óleo residual, resultante da fritura, pode ser utilizado como fonte energética na dieta, já que grande quantidade é impropriamente descartada, tornando-se um problema ambiental. No entanto, a inclusão de ingredientes alternativos na dieta pode causar desequilíbrios entre o ingresso, o egresso e a metabolização dos nutrientes no tecido animal. A quebra deste equilíbrio (homeostase) leva a redução do desempenho zootécnico (González, 2000), além da possibilidade de doenças subclínicas de difícil percepção; limitando a produção de modo persistente (Roos, 2008). Estas enfermidades causam transtornos metabólicos que podem ser identificados através da patologia clínica veterinária, por meio de exames laboratoriais de sangue, como a análise do hemograma e da bioquímica sérica, além do exame físico dos animais; subsidiando assim, diagnósticos mais precisos e evitando-se prejuízos econômicos.

Teve-se por objetivo neste estudo avaliar os parâmetros bioquímicos séricos de ovinos confinados recebendo dietas contendo óleo de soja ou óleo de soja residual (descarte de cozinha).

\section{MATERIAISE MÉTODOS}

O experimento foi conduzido nas dependências da Unidade Animal de Estudos Digestivos e Metabólicos do Departamento de Zootecnia da Faculdade de Ciências Agrárias e Veterinárias (FCAVUnesp), Campus de Jaboticabal/SP, Brasil.

Foram utilizados 24 borregos, mestiços (Santa Inês $\times$ Dorper), não castrados, com aproximadamente $25 \mathrm{~kg}$ de peso corporal alojados em baias individuais, providas de comedouro individual e bebedouro coletivo.

Os animais foram distribuídos em delineamento em blocos casualizados (de acordo com o peso corporal inicial), com três tratamentos e oito repetições. Os animais foram submetidos a três dietas experimentais: $\mathrm{C}=$ dieta controle, sem adição de óleo; $S=$ dieta com inclusão de $6 \%$ de óleo de soja; e R= dieta com inclusão de $6 \%$ de óleo de soja residual de fritura. Os tratamentos, na forma de dietas isoproteicas $(18,4 \%$ PB), foram formulados na proporção

Tabela I. Porcentagem dos ingredientes $e$ estimativa da composição bromatológica dos tratamentos experimentais (\% MS) de dietas de ovinos alimentados com fontes de lipídios. (Ingredients percentage and estimative of the chemical composition of the experimental treatments (\%DM) of sheep diets fed lipid sources).

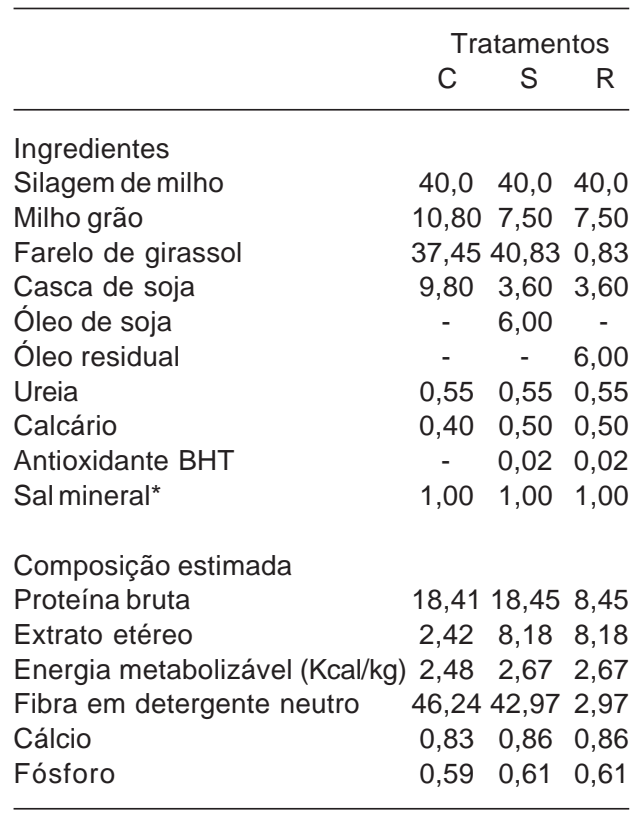

$\mathrm{C}=$ dieta controle; $\mathrm{S}=\mathrm{C}$ com $6 \%$ de óleo de soja; $\mathrm{R}=\mathrm{C}$ com $6 \%$ de óleo de soja residual.

${ }^{*}$ Composição por kg: Ca: 100 g; P: 60 g; Mg: 10 g; S: 25 g; Na: 195 g; Cl: 300 g; Co: 100 mg; Fe: 1200 mg; Se: 12 mg;Zn: 4000 mg; F: 600 mg;Cu: $600 \mathrm{mg}$. 


\section{ÓLEO DE SOJA E ÓLEO DE SOJA RESIDUAL PARA OVINOS}

volumoso:concentrado de 40:60, de acordo com o NRC (2007), em que a silagem de milho foi utilizada como volumoso e o concentrado era composto por milho grão inteiro, casca de soja, farelo de girassol, ureia, sal mineral, calcário e antioxidante (tabela I). O óleo residual, oriundo da fritura de batatas, foi recolhido semanalmente em restaurantes da cidade local, estocados em galões de cor escura e em lugar fresco, arejado e sombreado e adicionado no momento de preparo da ração, ainda na fábrica.

O experimento teve duração de 80 dias, sendo 21 dias de adaptação. A colheita de sangue foi realizada no último dia do período experimental, através da punção da veia jugular, utilizando tubos Vacutainer ${ }^{\circledR}$. As amostras de sangue foram encaminhadas ao Laboratório do Departamento de Clínica e Cirurgia Veterinária, e com auxílio de kits comerciais Labtest ${ }^{\circledR}$ foram quantificados os seguintes parâmetros: glicose, triglicérides, colesterol e proteínas totais, e as enzimas aspartato aminotransferase (AST), gama glutamiltransferase (GGT) e fosfatase alcalina (FAL).

Tabela II. Concentrações séricas das enzimas AST, GGT e FAL de ovinos alimentos com diferentes fontes de lipídios. (Serum concentrations of AST, GGT and ALP of sheep fed differents lipid sources).

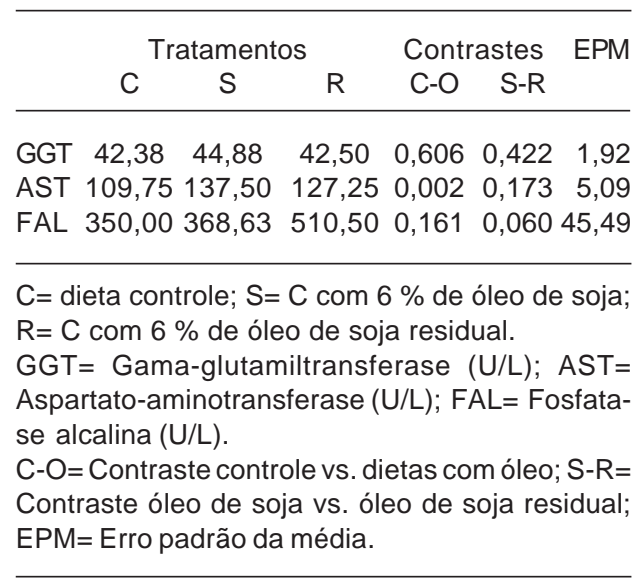

Tabela III. Concentrações séricas de glicose, triglicérides, colesterol e proteínas totais de ovinos alimentados com diferentes fontes de lipídios. (Serum concentration of glucose, triglycerides, cholesterol and total protein of sheep fed differents lipid sources).

\begin{tabular}{|c|c|c|c|c|c|c|}
\hline & \multicolumn{3}{|c|}{ Tratamentos } & \multicolumn{2}{|c|}{ Contrastes } & \multirow[t]{2}{*}{ EPM } \\
\hline & C & S & R & C-O & S-R & \\
\hline GLI & 76,06 & 74,17 & 67,46 & 0,389 & 0,340 & 5,58 \\
\hline COL & 36,96 & 52,04 & 50,61 & 0,004 & 0,778 & 4,44 \\
\hline TRI & 19,43 & 21,97 & 22,75 & 0,330 & 0,820 & 2,64 \\
\hline PROT & 6,91 & 7,16 & 6,94 & 0,655 & 0,527 & 0,23 \\
\hline
\end{tabular}

$\mathrm{C}=$ dieta controle; $\mathrm{S}=\mathrm{C}$ com $6 \%$ de óleo de soja; $\mathrm{R}=$ C com $6 \%$ de óleo de soja residual.

$\mathrm{GLI}=$ Glicose $(\mathrm{mg} / \mathrm{dL}) ; \mathrm{COL}=$ Colesterol $(\mathrm{mg} / \mathrm{dL})$; $\mathrm{TRI}=$ Triglicérides $(\mathrm{mg} / \mathrm{dL}) ; \mathrm{PROT}=$ Proteínas totais (mg/dL).

$\mathrm{C}-\mathrm{O}=$ Contraste controle vs. dietas com óleo; $\mathrm{S}-\mathrm{R}=$ Contraste óleo de soja vs. óleo de soja residual; $\mathrm{EPM}=$ Erro padrão da média.

Os dados foram analisados utilizandose o procedimento MIXED do programa estatístico SAS, versão 9.1. O animal foi considerado a unidade experimental e foram avaliados os contrastes entre o tratamento controle e os tratamentos com óleo (independente da fonte) $(\mathrm{C} v s(1 / 2 \mathrm{~S}+1 / 2 \mathrm{R}))$ e entre os tratamentos com diferentes fontes de óleo (S vs R). Na identificação dos efeitos foram consideradas significância de $5 \%$ e tendência de $10 \%$.

\section{RESULTADOSEDISCUSSÃO}

$\mathrm{A}$ adição de óleo à dieta, independente da fonte, promoveu alterações $(\mathrm{p}=0,002)$ nos valores séricos da enzima AST (tabela II). Apesar disso, os valores médios encontrados estão no intervalo normal sugerido por Kaneko et al. (2008) (60-280 U/L). Essa enzima é utilizada como indicador de dano à membrana do hepatócito, resultando no aumento da permeabilidade (González e Silva, 2006) Portanto, a adição de $6 \%$ de óleo de soja ou residual por 80 dias, não foi 


\section{SCARPINO, EZEQUIEL, SILVA E VAN CLEEF}

suficiente para causar danos irreversíveis à saúde dos animais.

No que diz respeito à enzima GGT, não foi evidenciado efeito da adição de óleo, e os valores médios estão no intervalo considerado ideal para animais dessa espécie (20$52 \mathrm{U} / \mathrm{L})$. Apesar de não ter sido observado efeito da adição das fontes de óleo sobre a enzima FAL, houve uma tendência $(\mathrm{p}=0,06)$ de aumento nos valores séricos dessa enzima quando foi adicionado óleo residual à dieta (tabela II), e os valores observados neste tratamento estão acima do recomendado por Kaneko et al. (2008) (68-387 U/L). Valores elevados de FAL podem sugerir osteopatia e a ocorrência de hepatopatia acompanhada de colestase (Meyer et al., 1995; Silva et al., 2004).

Não houve efeito $(p>0,05)$ dos tratamentos sobre a concentração de glicose,

\section{BIBLIOGRAFIA}

Brito, A.M.; González, F.D.; Ribeiro, L.A.; Campos, R.; Lacerda, L.; Barbosa, P.R. e Bergmann, G. 2006. Composição do sangue e do leite em ovinos leiteiros do sul do Brasil: variações na gestação e na lactação. Ciênc Rural, 36: $942-$ 948.

González, F.H.D. 2000. Uso de perfil metabólico para determinar o status nutricional em gado de corte. In: González, F.H.D.; Barcellos, J.; Patiño H.O. e Ribeiro, L.A. (Eds.). Perfil metabólico em ruminantes: seu uso em nutrição e doenças nutricionais. Gráfica da Universidade Federal do Rio Grande do Sul. Porto Alegre. pp. 63-74.

González, F.H.D. e Silva, S.C. 2006. Introdução à bioquímica clínica veterinária. Universidade Federal do Rio Grande do Sul. Porto Alegre. $358 \mathrm{pp}$.

Kaneko, J.J.; Harhey, I.W. and Bruss, M.L. 2008. Clinical biochemistry of domestic animal. Academic Press. San Diego. 928 pp. triglicérides e proteínas totais (tabela III), as quais estão nos intervalos sugeridos como normais pela literatura (Kaneko et al., 2008; Brito, 2006). A adição das duas fontes lipídicas aumentou a concentração sérica de colesterol $(\mathrm{p}=0,004)$ para valores dentro do intervalo considerado como normal por Kaneko et al. (2008) (50-76 mg/dL); enquanto que a dieta sem óleo não propicia níveis séricos adequados de tal parâmetro, podendo causar déficits no metabolismo energético animal.

\section{CONCLUSÕES}

A inclusão de $6 \%$ de óleo de soja e de óleo de soja residual na dieta de ovinos confinados aumenta as concentrações de colesterol e da enzima AST. Porém, tais alterações não são suficientes para causarem prejuízos à saúde animal.

Meyer, D.J.; Coles, E.H. e Rich, L.J. 1995. Medicina de laboratório veterinário: interpretação e diagnóstico. Editorial Roca. São Paulo. 308 pp.

National Research Concil - NRC. 2007. National Research Council. Nutrient requirements of sheep. $1^{\text {a }}$ ed. National Academy of Science. Washington. 384 pp.

Roos, T.B.; Vendramin, L.; Schwengler, E.; Goulart, M.A.; Quevedo, P.S.; Silva, V.M.; Verde, P.M.L.; Del Pino, F.A.B.; Timm, C.D.; Gil-Turnes, C. e Correa, M.N. 2008. Avaliação de parâmetros do perfil metabólico e do leite em diferentes categorias de vacas leiteiras da raça Jersey em rebanhos do Sul do Rio Grande do Sul. Vet Foco, 5: 121-130.

Silva, S.L.; Fagliari, J.J. e Cesco, F.T.R.S. 2004. Atividade sérica das enzimas AST, ALP e GGT de caprinos das raças anglo-nubiana e saanen criados nos Estados de São Paulo e Paraíba. Ars Vet, 20: 022-027. 